\title{
Emerging Technology in the Construction Industry: Perceptions from Con- struction Industry Professionals
}

\section{Prof. Eric A Holt, University of Nebraska - Kearney}

Eric A. Holt is an Assistant Professor at the University of Nebraska-Kearney, teaching in the Construction Management program. He has 23 years of industry experience, with 16 years in the design field. He teaches Plan Reading, Virtual Design and Construction, BIM, and Building Codes to CM Majors.

\section{Mr. James M Benham, JBKnowledge, Inc.}

James is now the President and CEO of JBKnowledge, Inc. and a highly acclaimed construction technology public speaker. JBKnowledge specializes in IT solutions for the construction and insurance industries and is the maker of the SmartBidNet, SmartCompliance, and SmartReality cloud solutions. JBKnowledge specializes in enterprise application and database development, electronic data interchange, strategy consulting, mobile solutions, and web development, focusing on the construction and insurance industries. As a rapidly growing business year after year, JBKnowledge is a six-time recipient of the Aggie 100 award, six-time Newman 10 recipient, and was recently named to the LSU One Hundred for the first time. The company, and James, are headquartered in Bryan/College Station, TX with offices around the U.S.A. and in Argentina.

\section{Dr. Ben Fitzgerald Bigelow, Texas A\&M University}

Dr. Bigelow Joined the faculty at Texas A\&M in August of 2011. Dr. Bigelow earned a BS in construction science at Texas A\&M, an MS in construction management at Arizona State University, and his PhD from The School of Education at Colorado State University. He teaches Estimating and Residential Capstone. His research interests are generally related to affordable and sustainable residential construction, construction higher education, underrepresented groups in construction, and technology in construction. Dr. Bigelow holds the professional designations of: AC (Associate Constructor) from the American Institute of Constructors and CGP (Certified Green Professional), CAPS (Certified Aging in Place Specialist, and RCS (Residential Construction Superintendent) from the National Association of Home Builders Dr. Bigelow serves as the Texas A\&M NAHB student chapter's faculty advisor, and competition team coach. He is a member of the NAHB student chapters advisory board, and is a former member of the NAHB education committee. Professionally Dr. Bigelow spent three years building production homes in Phoenix, Arizona and Dallas, Texas. He has also operated his own design built remodeling firm since 2001, providing remodeling, consulting, and expert witness services. 


\title{
Emerging Technology in the Construction Industry: Perceptions from Construction Industry Professionals
}

\begin{abstract}
Although historically the construction industry has been a slow adopter of technology, in recent years the technology available to increase productivity and thus profit margins has seen rapid adoption and advancement. As these advances have taken hold the need for students to be exposed to this technology, to better prepare them for their careers has arisen. Project management, estimating and building information modeling (BIM) technologies are now commonly found in construction higher education. However, as technology in the construction industry continues to advance educators must be aware of what the "cutting edge" of technology in construction is, so they can expose their students to it, and more thoroughly prepare them for what they will interact with in their careers. This study utilized a survey of construction industry professionals to learn about advances in technology and where they are being used. The internet based survey netted more than 1,000 responses and produced a sample for each question that ranged from $n=116$ to $n=1,014$. Specifically this study sought to learn about the use of augmented and virtual reality technology, the technology that industry professionals have seen and hope to see used in future projects, and the barriers to technology adoption. The study provides recommendations for technologies that should be introduced to students beyond computer applications for estimating, scheduling and BIM. Further this study provides construction educators and professionals alike an idea of the direction technology is going in the industry.
\end{abstract}

\section{introduction}

The project-based nature of the construction industry, the highly complex communication structure on projects, and the large amount of data general contractors deal with all demonstrate the need for efficiency in managing the construction process. Technology has simplified the construction process, but this technology has not yet achieved the productivity gains possible because of the lack of integration between applications ${ }^{8}$.

There is an undeniable need for efficiency in managing the construction process, and emerging technology offers perhaps the best opportunities to improve the construction process through better integration and efficiency. Over the last 40 years productivity had remained largely unchanged in construction, while every other U.S. industry has achieved productivity gains through technology ${ }^{14}$. The fundamental nature of the construction industry to resist change is likely a root cause of slow technology adoption, but regardless of the cause, construction higher education has a responsibility to lead change. To help the construction industry improve through the adoption of technology, students in construction related degree programs should be exposed to the technology that is emerging in the construction industry so that as future advances are made they are more readily adopted and implemented in the construction process.

Use of any technology in the classroom might help to increase the use of technology in the construction industry, but to maximize the potential impact, educators should ensure that 
technology incorporated in the classroom will benefit students when they enter the industry. Knowing what technology is being used, and what emerging technologies are gaining traction in the construction industry, is vital for educators to choose what technology that should be incorporated into their courses. The need for that information led to the research questions of this study:

- What is the level of interest and adoption in augmented or virtual reality (AR/VR), and wearable technology in the construction industry?

- What are the emerging technologies that construction industry professionals are most interested in?

- What are the barriers to technology adoption in the construction industry?

This research is needed because it provides educators a better source of information about technology than individual opinions from construction professionals, or the word of a salesman trying to sell a specific product. This study is significant because it collected data from hundreds of construction industry professionals, to provide an empirical look at emerging technology, in construction in 2014.

\section{review of literature}

The construction industry has witnessed three distinct eras in information technology (IT) ${ }^{7}$. These eras started with stand-alone tools on a computer like computer aided drafting (CAD). Next came a focus on communications, using email and related tools. Currently we are in the $3^{\text {rd }}$ era $^{3}$, which is focused on interoperability and integration between the tools adopted in the previous eras. The different eras of IT in the construction industry provide documentation of the adoption of technology in the construction industry ${ }^{3}$. However, as reported by Sabol (2007) the adoption has not resulted in an increase in productivity ${ }^{14}$.

In the recent past emerging technology in the construction industry has focused on communication and collaboration, as the benefits to the construction process by improvement in these areas is obvious ${ }^{18,11}$. Two types of technology have dominated in these areas, building information modeling (BIM), which has established a solid reputation for collaboration ${ }^{2}$, and cloud computing, which has emerged more recently as a solution for collaboration ${ }^{1,10,12}$. While aspects of BIM and cloud computing continue to emerge, in general they are rapidly becoming a typical component in the construction process, whereas a few years ago they were cutting edge. Because of this rapid pace of change knowing what direction technology is heading is vital.

Technology in construction education should reflect that of the industry, but a variety of challenges to technology use in a university exist including: economics and policy at a governmental level, commercial concerns of IT vendors, managerial concerns of university administration, and strategic student concerns ${ }^{15}$. Despite these barriers it has been found that some technology in construction education sacrifices little or nothing, rather it is more efficient ${ }^{17}$, and that it can be used as an effective motivator for students in construction disciplines 5 .

With the ability to improve the construction industry as well as construction education, emerging technology and the direction of technology should be of prime interest to educators. 


\section{methodology}

This research used a mixed methods approach utilizing survey responses that were both scale and open ended. A web-based, cross sectional survey was used to provide a sample representative of the construction industry across the United States, so that findings could be generalized to the U.S. construction industry. Quantitative findings were analyzed using descriptive statistics, while qualitative results were coded and evaluated for common themes. Data was collected in 2014 and IRB approval was obtained.

Because the survey did not measure constructs and asked participants for responses regarding attribute variables, no formal evaluation of internal validity was performed on the survey. However, because this survey was also conducted in 2012 and 2013, the researchers have confidence in the survey's ability to collect the desired information, as the previous iterations served to refine the survey.

The survey used to collect data for this study was distributed directly and indirectly to construction industry professionals. To access a sufficient number of construction industry professionals, the survey was sent (e-mailed) directly to: the clients and prospects of Company 1, the construction industry advisory council (IAC) at University 1, and the members of Association $l$ (A1). Indirectly, participation was requested through social media where the link to the survey was posted on the accounts maintained by Company 1, the IAC at University 1, and A1. Also snow-ball sampling was used, where each survey participant was asked to forward the survey along to their contacts in the construction industry. Over the four and a half week period that the survey was open, a total of 1,284 responses were received, and after filtering 1,028 usable surveys remained. A response rate could not be calculated because the total number of individuals invited to participate could not reliably be determined.

With a confidence level of $95 \%$, and confidence interval of 5, and a population of 485,000 construction managers in the U.S. (BLS, 2012), a sample size of 384 was needed for each question. Despite obtaining 1,028 usable survey responses, after pairwise deletion, the actual sample size for each question varied from $n=116$ to $n=1,014$. As a result the generalizability of the findings, to the population at large, depends on the on the individual question and its sample size.

\section{findings \& discussion}

As was the goal of the researchers, responses came from a broad cross section of construction industry professionals whose responsibilities ranged from preconstruction and operations to administrative and executive. Data filtering was used to ensure only responses from construction or construction service providers were included in the analysis.

Employees from both small and large companies participated. Higher participation among larger companies was expected as there are more employees at those companies and more potential participants. Table 1. Shows the specific break down of responses based on company size. 
Table 1. Annual Sales Volume of Respondent's Companies $n=942$

\begin{tabular}{cc}
\hline Annual Sales Volume & Percent of Participants \\
\hline Less than \$1 Million & $5.7 \%(54)$ \\
\$1-5 Million & $6.6 \%(62)$ \\
\$6-20 Million & $14.9 \%(140)$ \\
\$21-50 Million & $17.2 \%(141)$ \\
\$1-100 Million & $15 \%(141)$ \\
$+\$ 100$ Million & $40.6 \%(383)$ \\
\hline
\end{tabular}

To explore the adoption of current technology among participants, they were asked how many construction specific applications they use in their jobs. As shown in Table 2, construction managers are utilizing three to four construction specific applications in their jobs. A notable percent $(18 \%)$ are using six or more. Among the small percentage (3\%) who reported 0 applications, nearly all came from companies doing less than 10 million in sales volume per year.

Table 2. Number of Construction Software Applications Used in Job $(n=866)$

\begin{tabular}{cc}
\hline Number of Applications & Percent of Participants \\
\hline 0 & $3.7 \%(32)$ \\
1 & $12.5 \%(108)$ \\
2 & $18.6 \%(161)$ \\
3 & $24.8 \%(215)$ \\
4 & $13.7 \%(119)$ \\
5 & $8.4 \%(73)$ \\
$6+$ & $18.2 \%(158)$ \\
\hline
\end{tabular}

These results indicate almost industry wide use of at least one construction specific computer application, and the high percentage (65\%) of respondents using three or more construction applications supports the increased adoption of technology in the industry, and the important role(s) emerging technology will play in the construction industry going forward.

To explore future technology interest and adoption among participants, they were asked what other new technologies they have seen and hope to see applied in future construction projects, or that their company was experimenting with or using on a project. Building Information Modeling (BIM), augmented/virtual reality, wearable technology, laser scanning, and drones were the top responses of future technology topics.

\section{building information modeling (BIM)}

Building Information Modeling (BIM) is an emerging technology in the construction industry, though the concepts of BIM have been around for many years. The automobile, aircraft, and computer industries have been transformed through performing similar product design and delivery practices of BIM ${ }^{9}$. The concept of BIM is to build the project virtually, so that all facets of the project can be planned out before site construction begins. This level of preplanning includes spatial coordination of all the materials, labor, and sequencing for the construction of the project, and then allows for the virtual planning of how the building will be used and reused 
by the proposed owner after construction ${ }^{6,16}$. A basic premise of BIM is collaboration by different stakeholders at different phases of the life cycle of a facility to insert, extract, update or modify information in the BIM to support and reflect the roles of that stakeholder ${ }^{4}$. BIM is very heavily based on technology, especially software, to manage all the data and the process. It is extremely important to have good interoperability; the ability to manage and communicate electronic product and project data among collaborating software, individuals, design teams, and firms. If all members of the collaborating team can freely exchange data across different platforms and applications, every member of the team can better manage the BIM and project delivery process.

A large portion of the survey participants are utilizing BIM, and the researchers did not consider BIM as future technology. However, thirty-eight percent of the participants answered that they are not using a BIM solution and consider it future technology. There is still a large portion of the construction market waiting and watching to see how BIM can be implemented into a project, what the return on investment will be, and how the different software integrates together. Many participants feel that the collaboration side of BIM has not yet proven itself, and it is a future technology they are watching or experimenting with. The participants who are working with BIM are now looking at and experimenting with augmented and virtual reality.

\section{augmented/virtual reality}

Virtual and augmented reality differ in that augmented reality uses real-world imagery overlaid on computer generated data, while virtual reality produces an experience totally independent of the real-world. While there is certainly a great deal of work involved behind the scenes on this technology, it is of interested because of its intuitive nature, that makes anyone able to use it. Its application in construction comes in requiring one to simply point their mobile device at a realworld target and the technology does the rest, allowing users to interact with plans, compare planned and actual completion, guide machinery, secure workers, and document progress.

Regarding this technology participants were asked simply if their companies are using an augmented or virtual reality solution. From 1014 responses, the results indicate that this technology has yet to taken hold in construction with only 24 (2\%) respondents indicating their company is using it. These results are displayed in figure 1.

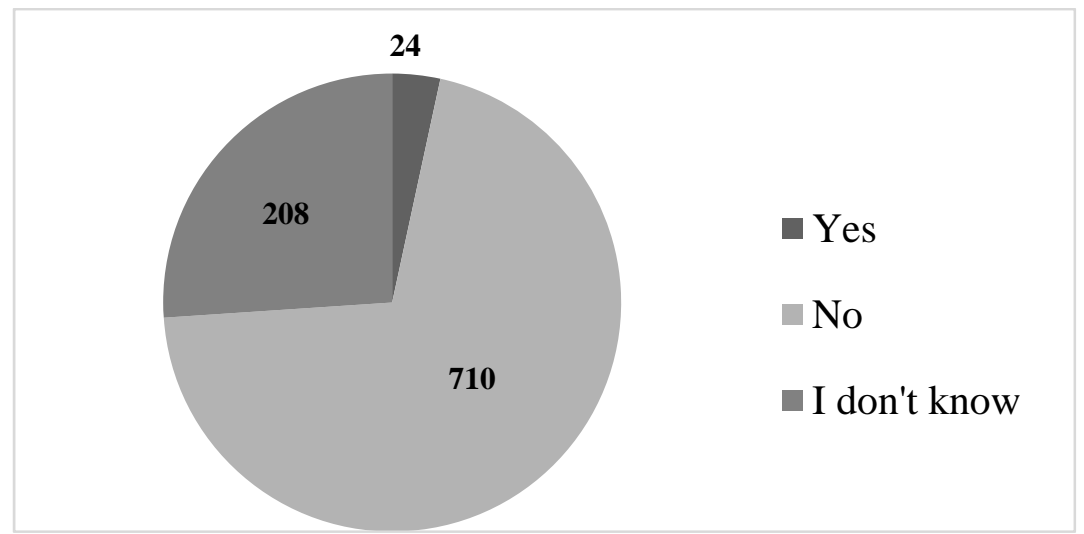

Figure 1. Use of Augmented or Virtual Reality. 
Among the 24 positive responses some specific applications were reported, the applications most commonly reported were: AR-Media, Augment, Aurasma, Oculus Rift, Smart Reality, VMWare, and 3DSMax. There are a variety of options available for AR/VR implementation in construction, however the meager usage seems to indicate that none of them have found the right combination of technology and price point. This technology also is related to the future of wearable technology in the construction industry.

\section{wearable technology}

Wearable technology in construction ranges from health monitoring devices to Google Glass. The advantages of wearable technology is that they can provide real time data about an individual or project and it can eliminate the need to carry and point a portable device to access the power of AR/VR. With products like Google Glass, Epson's Moverio BT-200 smart glasses, and Oculus' Rift headset, the advantages of AR/AV are accessible hands free, which allows for the integration of motion sensors so individuals can use their hands to interact with the environment rather than using them to hold a device. This technology has abundant opportunity in construction specific applications, but it also has the ability to eliminate the need for mice, keyboards, and even touch screens. However like AR/VR technology, wearable technology has not yet seen large scale use. With only $2.5 \%$ percent reporting their company uses it. Figure 2 displays these results. Bluetooth headsets, Fitbit (health tracking), Google Glass, and Go Pro cameras were reported. However five respondents indicated their smart devices (tablets or phones) wear wearable technology. These devices probably do not belong in the wearable technology category, making the actual percentage more like $1.8 \%$ (13 out of 708 ).

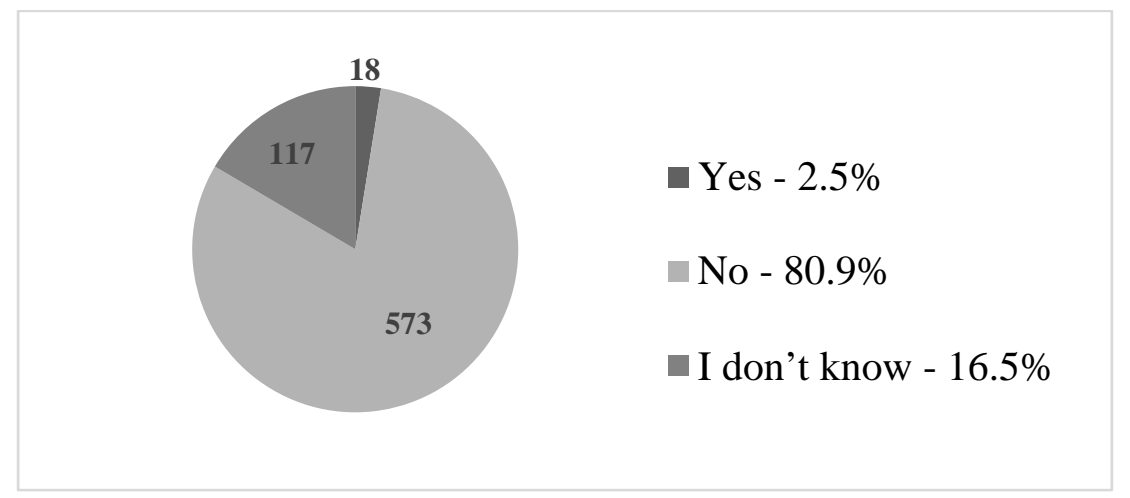

Figure 2. Use of Wearable Technology

emerging technology

Other emerging technology, related to BIM, augmented reality, and wearable technology noted by the participants were; 3D laser scanning and printing, the use of mobile devices for data collection and communication in the field, and the use of drones to monitor the construction site. $3 \mathrm{D}$ laser scanning is utilized by the participants who do a lot of renovation work. It is augmented reality in reverse. By creating a digital image of the existing space, the design team can then manipulate the existing space virtually utilizing BIM, and then the proposed space can be overlaid back onto the existing to see the augmented space. Some of the participants are 
experimenting with iPlan tables, tablets, iPads, and other mobile technology to communicate proposed spaces to the field, and to gather and return data back from the field to the office. A select few of those are also monitoring the field through the use of drones and go pro cameras.

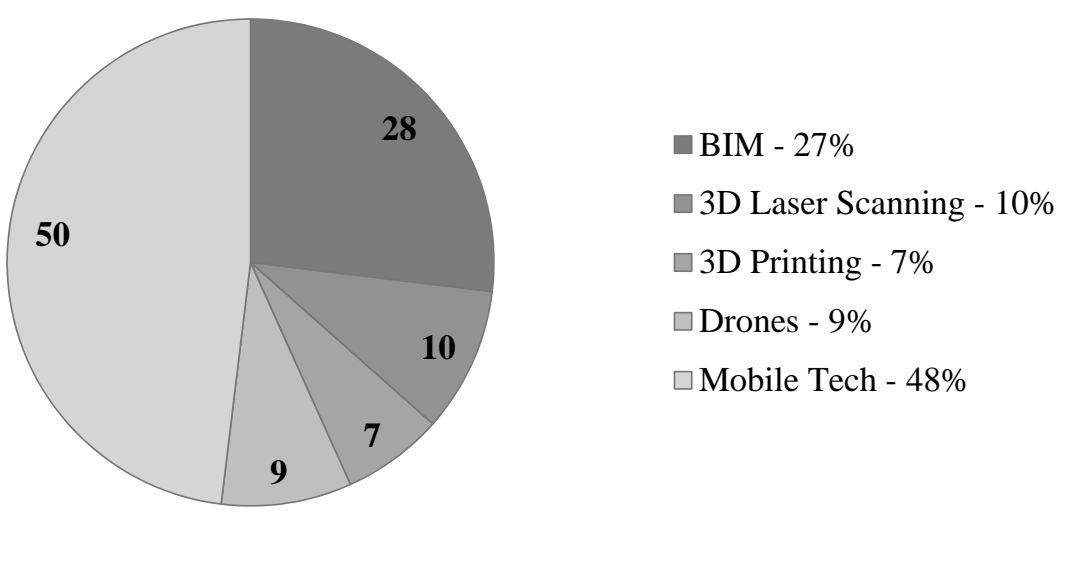

Figure 3. Emerging Technology

barriers to adoption

The participants were asked: "What was the most limiting factor in trying and/or adopting new technology?" The majority responded that budget was the number on limiting factor (53.35\%). The next two responses were lack of staff support for the new technology (36.5\%), and waiting to see if the technology was more than just a toy $(36.1 \%)$. A lack of knowledge about what the new technology(s) are, was the fourth limiting factor (33.1\%). They just don't know what is the next big thing is in technology for the construction industry. The next two limiting factors were management hesitancy, followed by employee hesitancy. A select few $(7.5 \%)$ reported that they don't have any limitations in trying and/or adopting technology, these professionals are likely employed at the companies who are leading the way with technology usage in construction.

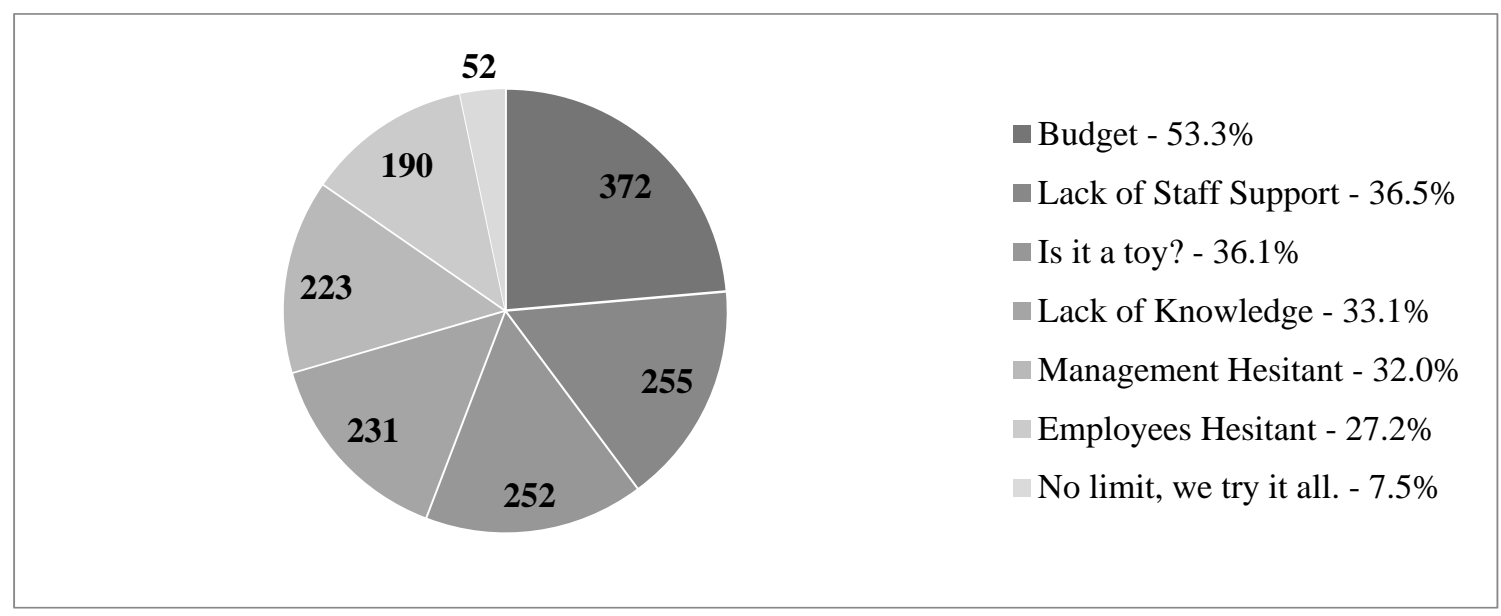

Figure 4. Adoption Limiting Factors 


\section{conclusions}

Construction higher education has a responsibility to train students for the work they will perform, so it is incumbent on educators to keep abreast of technology in the industry. With most people using three or more construction specific applications daily, technology is advancing construction management. BIM continues to be the leader of advancing technology, and a lot of emerging technology falls under the BIM umbrella. Augmented reality, 3D laser scanning and printing, wearable, mobile, and drone technology are all about more efficiently gathering and communicating information about the project. The limiting factors to new technology adoption are primarily budget related, but as the price of technology decreases, and the returns in productivity increase, and become more obvious, there will be more and more construction professionals integrating the technology into their construction process.

\section{references}

1. Abedi, M., Fathi, M.S., \& Rawai, S. (2012). Cloud computing technology for collaborative information system in construction industry. Innovation and Sustainable Competitive Advantage: From Regional Development to World Economies. 593-602.

2. American Institute of Architects (AIA). (2007). "Integrated Project Delivery: a Guide". AIA National and AIA California Council.

3. Arnold, P., \& Javernick-Will, A. (2012). Projectwide Access: Key to Effective Implementation of Construction Project Management Software Systems. Journal of Construction Engineering and Management, 139(5), 510-518

4. Committee, T. N. B. I. M. S. P. (2007). "The National BIM Standard." from HTTP://WWW.FACILITYINFORMATIONCOUNCIL.ORG/BIM/FAQ.PHP.

5. Duckworth, L., Sulbaran, T., Strelzoff, A., Rapp, R. (2011). Motivation through collaborative virtual reality environments earthwork exercises. Proceedings of the $47^{\text {th }}$ Annual Conference of the Associated Schools of Construction, Lincoln, NE. Retrieved from http://ascpro.ascweb.org/main.php

6. Eastman, C. (2004). New Methods of Architecture and Building. ACADIA. Toronto, CA.

7. Froese, T. (2005). Impact of emerging information technology on information management. International Conference on Computing in Civil Engineering, ASCE, Cancun, Mexico, (Vol 8890, No. 10, pp. 12-15)

8. Gallaher, M. P., O’Conner, A. C., Dettbarn, J. L., Gilday, L. T. (2004). Cost Analysis of Inadequate Interoperability in the U.S. Capital Facilities Industry. National Institute of Standards and Technology, Gaithersburg, MD. Retrieved from: fire.nist.gov/bfrlpubs/build04/art022.html.

9. Jernigan, F. E. (2007). Big BIM little BIM: The practical approach to building information modeling: integrated practice done the right way. Salisbury, MD, 4Site Press.

10.Jiao, Y. B. (2013). The Design of the Logistics Information Sharing Platform Based on Cloud Computing. Advanced Materials Research 734: 3220-3223. 
11.Penland, J. L. (2002). Implementation of web-based team collaboration tools in the architectural, engineering and construction industry. Dissertation, University of Kansas.

12. Redmond, A., Hore, A., Alshawi, M., \& West, R. (2012). Exploring how information exchanges can be enhanced through Cloud BIM. Automation in Construction 24, 175-183.

13. Rogers, P. L. (2000). Barriers to adopting emerging technologies in education. Journal of Educational Computing and Research, 22(4), 455-472.

14. Sabol, L. (2007). Technology, Change, and the Building Industry. Real Estate Review 36(3), 87.

15. Selwyn, N. (2007). The use of computer technology in university teaching and learning: a critical perspective. Journal of Computer Assisted Learning, 23: 83-94. Doi: 10..1111/j.1365-2729.2006.00204.

16. Smith, D. (2007). "An Introduction to Building Information Modeling (BIM)." Journal of Building Information Modeling (BIM). (Fall 2007)

17. Smithwick, J. B., Mischung, J. J., Sullivan, K. T. (2014). Impact of Estimating software on Student Performance for Simple Quantity Takeoff Calculations. Proceedings of the $50^{\text {th }}$ Annual Conference of the Associated Schools of Construction. Blacksburg, VA. Retrieved from: http://ascpro.ascweb.org/main.php

18.Zhu, Y., \& Augenbroe, G. (2006). A conceptual model for supporting the integration of inter-organizational information processes of AEC projects. Automation in construction 15(2), 200-211 